\title{
Quantifying herbivory across a coral reef depth gradient
}

\author{
Rebecca J. Fox, David R. Bellwood* \\ School of Marine and Tropical Biology, and Australian Research Council Centre of Excellence for Coral Reef Studies, \\ James Cook University, Townsville, Queensland 4811, Australia
}

\begin{abstract}
Despite the widely accepted importance of herbivory as a determinant of reef benthic community structure, few studies have examined the relative contributions of individual species to ecosystem processes at the whole reef scale. This study quantifies the grazing impact of individual species of roving herbivorous fishes across an inner shelf fringing reef at Orpheus Island, Great Barrier Reef, Australia. Estimates of roving herbivore impact based on dawn to dusk observations of feeding rates, measurement of bite sizes and relative abundance revealed that the Orpheus Island system was dominated by 3 species: Scarus rivulatus, Chlorurus microrhinos and Siganus doliatus. The estimated impact of all 3 species varied significantly across the reef depth gradient, with the rate of disturbance peaking at the crest and decreasing significantly down the slope and across the reef flat. The estimated species-specific disturbance levels suggested that during the course of a single month $104 \%$ of a square metre area of the reef crest is grazed by $S$. rivulatus while $40 \%$ is subject to grazing by $C$. microrhinos. A total of $26 \mathrm{~cm}^{3}$ of algal material is removed from the same area by $S$. doliatus. Overall, there was a 240-fold decrease in grazing activity across the reef flat from that at the crest. The pattern of grazing impact of the numerically dominant siganid and scarid fishes was negatively correlated with the distribution of macroalgae across the same reef gradient. The results of the current study provide support for the hypothesis that algal community structure is shaped by levels of herbivory.
\end{abstract}

KEY WORDS: Coral reef · Herbivore disturbance - Ecosystem impact · Macroalgae · Fishes · Resilience Resale or republication not permitted without written consent of the publisher

\section{INTRODUCTION}

Herbivores are a primary determinant of coral reef community structure (Steneck 1988, Choat 1991) and within this trophic grouping, reef fishes play a preeminent role (Mumby et al. 2006). Herbivorous fishes are estimated to be responsible for removing between 20 and $90 \%$ of the net daily production of the algal community (Hatcher 1983, Polunin \& Klumpp 1992), ensuring that its biomass turns over once every 4 to 25 d (Klumpp et al. 1987, Klumpp \& Polunin 1989). The interaction between herbivores and algae is probably the largest trophic flux on reefs (Hatcher 1981, Carpenter 1986) and historically this has been the context in which the importance of herbivory has been viewed.
Numerous experimental studies based on the exclusion of herbivores from areas of reef have demonstrated the importance of macroherbivores on algal standing crop and patterns of algal community succession (e.g. McClanahan 2003, Russ 2003). On a large scale, the effects of removal of herbivores by overfishing of reefs, particularly in the Caribbean, has further highlighted the importance of the role that the group plays in determining algal community succession and maintaining a healthy balance between corals and algae (Hughes 1994, McClanahan et al. 2003, Mumby et al. 2006).

Recently, however, a new perspective on herbivory and the importance of herbivores on coral reefs has emerged. Literature examining the process of degradation experienced by many of the world's coral reefs 
has advocated a system-level approach to reef ecology (e.g. Nyström et al. 2000, Bellwood et al. 2004, Hughes et al. 2005). The idea of a system-level approach is not new (see Hatcher 1983, Steneck 1988). However, the utility of the concept has been rediscovered as a framework for analysing the process of reef degradation and maintaining or enhancing reef resilience.

A system-level approach views reef dynamics in terms of a non-equilibrium environment with multiple stable states. Events such as global warming, eutrophication, or over-fishing have become re-cast as disturbance factors that have the potential to dislodge the system from its initial position and shift it to a new state (Nyström et al. 2000, Bellwood et al. 2004). The resilience of the reef system, therefore, reflects the size of disturbance that can be absorbed by the system without causing a shift to a new, usually undesirable state (Nyström et al. 2000). Herbivores confer resilience to the extent that they exert a grazing impact that maintains a balance between corals and algae.

Herbivory from the system perspective is not just viewed as an overall process of energy transfer, but rather a composite function of the individual impacts that each herbivorous species has on the system. Thus, the ability of a reef to withstand disturbance events and avoid shifts to alternate states will be dependent on having the right functional composition of herbivores. Herbivory viewed from the system perspective essentially poses the question: What is the relative importance of the various herbivorous species to the system? The ability to understand the role and relative importance of herbivorous species requires an understanding of the quantitative impact that each species has and the area in which it exerts that functional impact. As recent reviews have emphasized, the current dataset of quantitative ecosystem impacts of individual taxa is limited (McManus \& Polsenberg 2004). A number of detailed studies have laid the foundations for this type of analysis, especially in the Caribbean (e.g. Lewis \& Wainwright 1985, Bruggemann et al. 1994 , 1996) where system level analyses are now possible (e.g. Mumby 2006). Indo-Pacific examples are largely restricted to measurement of parrotfish bioerosion (e.g. Bellwood et al. 2003) and algal ingestion rates of selected parrotfish, surgeonfish, or damselfish species (e.g. Polunin \& Klumpp 1992, Polunin et al. 1995).

The limited dataset of measured ecosystem impacts for individual taxa partly reflects the historic tendency for herbivory to be viewed in terms of a uniform process (highlighted by Choat 1991). However, grazing by different groups of fishes can have different effects on the rate and trajectory of algal community succession (Hixon \& Brostoff 1996, Ceccarelli et al. 2005b) suggesting that community change is species-dependent.
The challenge of reef management posed by the system-level approach requires researchers and managers to go beyond the acknowledgment of the overall importance of the herbivorous trophic grouping and investigate the quantitative functional impacts of individual components of that group. This will strengthen management in that it enables the identification, and thus, the support of critical components within the herbivore guild. This study provides a first step in this endeavour. The aims of the present study, therefore, were to: (1) quantify the contribution of individual species of roving herbivores to levels of disturbance across an Indo-Pacific reef depth gradient; (2) determine the relative importance of individual species of herbivore at this location; and (3) relate the observed disturbance impact to algal community composition across the reef gradient.

\section{MATERIALS AND METHODS}

Study site and species. The study was conducted between October 2005 and January 2006 at Orpheus Island $\left(18^{\circ} 35^{\prime} \mathrm{S}, 146^{\circ} 20^{\prime} \mathrm{E}\right)$ in the inner shelf region of the Great Barrier Reef, Australia. Two sites at the north side of Pioneer Bay on the leeward side of the island were used in the study. Pioneer Bay displays a welldeveloped fringing reef with an extensive reef flat stretching approximately $150 \mathrm{~m}$ from the boulder shoreline to the reef crest. Within each site, 5 reef zones were defined (the slope, crest, inner, middle and outer flat) according to benthic composition. The inner reef flat was characterized by low coral abundance, patches of sand and high macroalgal abundance (particularly the pheophyte Sargassum). Coral cover was still low on the middle part of the reef flat where monospecific stands of the brown macroalgae Padina dominated. At the outer flat the consolidated substratum was covered by turf algae rather than macroalgae. Coral cover increased at the reef crest, but benthic cover was dominated by algal turf-covered consolidated pavement. The reef slope was defined by a $5 \mathrm{~m}$ depth limit and was characterised by high levels of sediment and detritus covered areas of dead coral substrate and coral rubble. These 5 zones formed the basis of the reef gradient referred to throughout this study. The fish species included in this study were roving (mobile) herbivorous and 'nominally' herbivorous (sensu Choat et al. 2002) members of the families Labridae (scarids), Acanthuridae, Siganidae, and Kyphosidae.

Roving herbivore distribution and abundance. Roving herbivore abundance and biomass across the study sites were estimated by conducting underwater visual censuses using SCUBA. Six censuses were conducted 
within each of the 5 zones at the 2 sites $(n=60)$. To minimize diver disturbance, censuses were based on 5 min timed swims along linear transects (the distances were subsequently calibrated using measuring tapes and marker buoys). They were performed by 2 divers simultaneously: one recording individuals greater than $10 \mathrm{~cm}$ total length (TL) in a $5 \mathrm{~m}$ wide transect; the other recording individuals 5 to $10 \mathrm{~cm}$ TL in a $1 \mathrm{~m}$ wide transect (following Bellwood et al. 2003). Fishes were grouped into $5 \mathrm{~cm}$ size classes for individuals greater than $10 \mathrm{~cm}$ and $2.5 \mathrm{~cm}$ size classes for individuals less than $10 \mathrm{~cm}$. Herbivorous and nominally herbivorous members of the family Pomacentridae were included in visual censuses to obtain data on the abundance of territorial species that could potentially interfere with feeding patterns of roving herbivores. Due to difficulties identifying juvenile Scarus, all individuals less than $10 \mathrm{~cm}$ were placed in the category Scarus spp. Chlorurus spp. (C. sordidus and C. microrhinos) are readily identifiable as juveniles. All visual censuses were conducted within $2 \mathrm{~h}$ of the morning high tide to minimize any tide or time of day effects.

Abundance estimates were converted to biomass estimates using published length-weight relationships (Kulbicki et al. 2005) with fish length taken as the midpoint of the respective size class. Analysis of the species composition of herbivore biomass at the 2 sites revealed that 3 species (Scarus rivulatus, Chlorurus microrhinos and Siganus doliatus) made up an average of between 64 and $89 \%$ of the total biomass of roving herbivorous fishes within each zone (Figs. 1 \& 2). It was, therefore, decided to base the quantification of herbivory within Pioneer Bay on the impact of these 3 species, since they were the dominant component of the herbivore assemblage at the study sites.

Calculation of daily disturbance impact of an individual. For all 3 species, the quantification of impact was based on a measure of the total number of bites taken over a day multiplied by the size of an individual bite. The effect of body size on impact was taken into account by dividing individuals of each species into

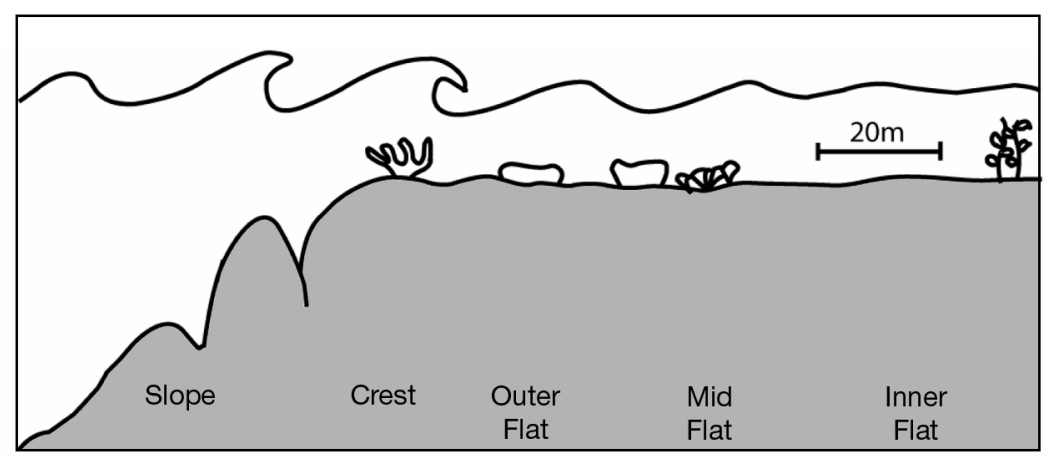

Fig. 1. Diagrammatic cross-section of coral reef with sector definitions
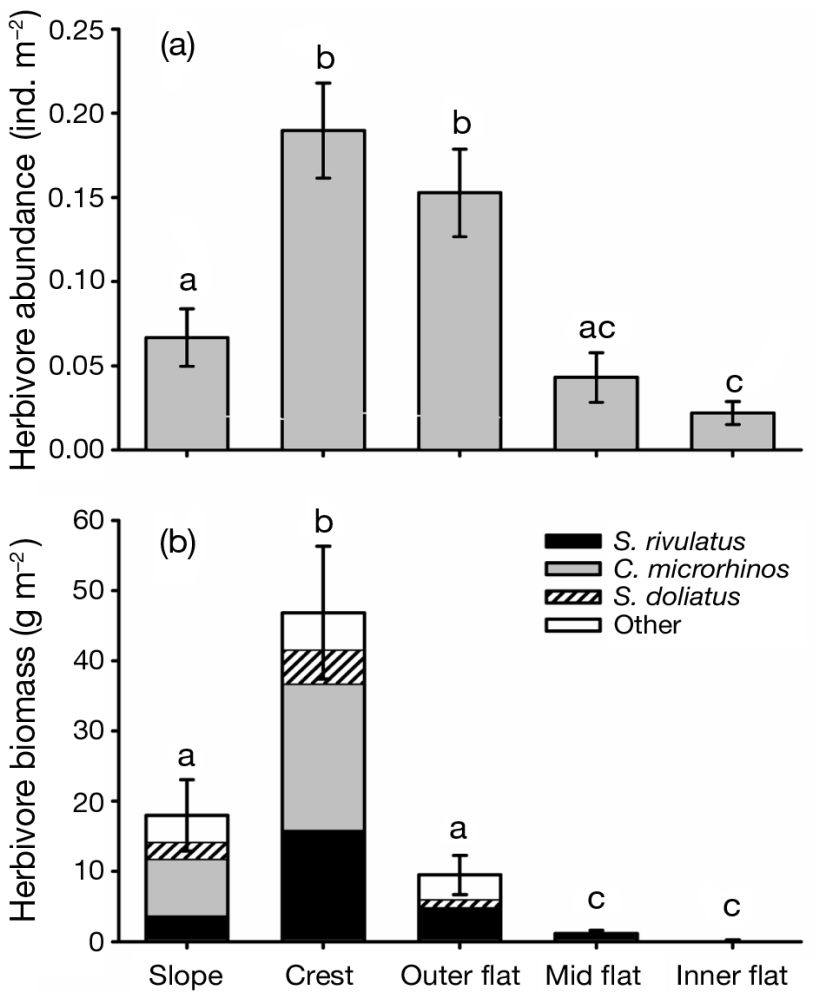

Fig. 2. Distribution of (a) total herbivore abundance (ind. $\mathrm{m}^{-2}$ $\pm \mathrm{SE}$ ) and (b) total herbivore biomass $\left(\mathrm{g} \mathrm{m}^{-2} \pm \mathrm{SE}\right.$ ) across the reef gradient at Pioneer Bay. Herbivore biomass is separated into contributions from Scarus rivulatus, Chlorurus microrhinos, Siganus doliatus and 'other', where 'other' represents contribution of the remaining 24 species of roving herbivorous fishes recorded in the visual censuses. Error bars represent SE of total roving herbivore biomass. Homogenous subsets (based on Student-Newman-Keuls [SNK] tests) are indicated with letters in common above the bars $(\mathrm{a}, \mathrm{b}, \mathrm{c})$

size classes and calculating each impact variable (number of bites per day and size of bite) separately for each size class. Scarus rivulatus individuals were divided into 3 size classes: small $(5-10 \mathrm{~cm})$, medium (11$25 \mathrm{~cm})$ and large $(>25 \mathrm{~cm})$; and Siganus doliatus individuals were grouped similarly: small $(5-10 \mathrm{~cm})$, medium $(11-20 \mathrm{~cm})$ and large $(>20 \mathrm{~cm})$. Only one size class of Chlorurus microrhinos individuals was examined $(>30 \mathrm{~cm})$ since fishes smaller than $30 \mathrm{~cm}$ were seldom observed and would, therefore, be expected to have minimal effect in terms of herbivory.

The total number of bites taken by an individual in a day was based on observations of the feeding rates of individual size classes of Scarus rivulatus, Chlorurus microrhinos and Siganus doliatus carried out over consecutive 
days across both sites. SCUBA based observations commenced at $06: 15 \mathrm{~h}$ to capture the start of feeding activity and continued until 18:00 h. The sample unit was a 2 to 5 min observation period for each fish, with the diver recording the start time of the observation and the total number of bites taken over a measured time interval. Observations were discontinued if the fish showed a marked response to the diver. A total of 476 independent observations were made for $S$. rivulatus, 133 for C. microrhinos and 489 for $S$. doliatus.

To calculate the total number of bites taken in the day, the recorded feeding rate (standardized to bites $\min ^{-1}$ ) was plotted against the time of day (in min) at which the observation had commenced. Following Bellwood (1995), a quadratic polynomial line was fitted to the data and the area under the line calculated by integrating the fitted equation from commencement to cessation of feeding. A value for the mean total number of bites taken in a day ( \pm SE) by an individual of one size class of a species was calculated from an average of the values obtained for the $4 \mathrm{~d}$ of observations ( $3 \mathrm{~d}$ for Chlorurus microrhinos). Among-day variation was comparable to, or exceeded, that among samples (pooled over the $4 \mathrm{~d}$ ) and, therefore, was selected as the primary source of variance to be incorporated when calculating compound variances.

The feeding action of Scarus rivulatus leaves a distinct grazing scar. For individuals greater than $15 \mathrm{~cm}$ TL, scars could be observed directly by divers and measurements of bite size were taken in the field. An individual was followed until the exact location of a bite could be seen. The TL of the individual was estimated and the maximum length $\left(L_{\max }\right)$ and width $\left(W_{\max }\right)$ of the feeding scar was measured using calipers. Measurements from whole and incomplete scars were taken in proportion to their occurrence on the reef. For fishes less than $15 \mathrm{~cm}$ TL, bite scars were too small to be observed directly in the field; therefore, laboratory methods were employed. Individuals were captured using a barrier net, measured (TL) and placed in aquaria with pieces of ungrazed turf-covered rock. After $3 \mathrm{~d}$, the rocks were removed and the maximum length and width of observable bite scars were measured under a dissecting microscope. The area of reef grazed or 'scraped' by each $S$. rivulatus bite was calculated as the product of $L_{\max }$ and $W_{\max }$ of each scar. Mean bite areas for each size class were calculated by averaging bite area values recorded for all individuals belonging to small $(\mathrm{n}=20)$, medium $(\mathrm{n}=$ $47)$ and large $(\mathrm{n}=39)$ size classes. For Chlorurus microrhinos (previously called C. gibbus), we used the bite area value reported by Bellwood (1995) $\left(169.99 \mathrm{~mm}^{2} \pm 18.05 \mathrm{SE}\right)$. The sizes of the individuals on which this bite area estimate was based were comparable with those in the current study.
The size of an individual bite of Siganus doliatus was estimated following the methods of Klumpp \& Polunin (1989). A total of 30 fish were captured by net on a nearby reef flat (with similar algal distributions) between 09:00 and 13:00 h, anaesthetized and placed on ice shortly after capture. The increase in gut content volume with time of day was then plotted against the cumulative bite rate for the same period. A regression line was fitted to the data to obtain a relationship between the number of bites taken and the gut content volume from which the mean volume ingested per bite could be calculated (the contents were overwhelmingly dominated by algae, although some attached sediment may have been included).

Total impact of a species across the reef gradient. The quantitative daily impact of an individual of each size class for each of the 3 species was calculated separately as the product of the mean bite size and the mean number of bites per day. This individual impact variable was then multiplied by the mean abundance of each size class obtained by visual census, giving a population-level estimate of the impact for that size class of that species per $\mathrm{m}^{2}$ in each of the 5 reef zones. The abundance of Scarus rivulatus $<10 \mathrm{~cm}$ was represented by Scarus spp. resulting in a small, but functionally insignificant, over-estimation of the impact of small $S$. rivulatus (adult $S$. rivulatus accounted for $88 \%$ of Scarus spp. at the study sites and it is assumed that juveniles would be a similarly dominant proportion).

For each species, the impacts of the 3 size classes were summed to give an overall estimate of the daily population impact of that species across each of the 5 reef zones. Compound error terms for the impact variables for each size class were calculated using an expanded 3-term version of Goodman's estimator (following Bellwood 1995). Goodman's estimator weights the variability associated with each variable in proportion to the relative size of the means of the other variables that make up the product 'impact'. Overall error terms for each species were calculated by summing error terms of the individual size classes (following Bruggeman et al. 1996).

Census of benthic composition. Benthic cover in each reef zone was quantified using a line intercept method. A $10 \mathrm{~m}$ transect tape was laid haphazardly across the reef substratum. A diver recorded the nature of the substratum directly underneath the tape at each $1 \mathrm{~m}$ interval and at points $1 \mathrm{~m}$ perpendicular to the left and right of the tape. Substratum type categories were: live coral, dead coral, turf algae $(<10 \mathrm{~mm}$ thallus height), macroalgae (>10 $\mathrm{mm}$ thallus height), damselfish territory, crustose coralline algae, and sand. A total of 6 replicates were conducted in each of the 5 reef zones at each site $(n=60)$. Data are presented as 
grazing rates $\mathrm{m}^{-2}$. However, it is noted that although some species feed on sand (Russ 1984), the proportion of sand or coral and surface topographic complexity may modify realized feeding intensities on algal covered surfaces.

Analyses. Total abundance of herbivores across the reef zones was compared using a 2-way ANOVA, with Site and Zone as fixed factors. Assumptions of normality and homogeneity of variance were inspected via residual plots and the data were square-root transformed to meet the assumptions. Total biomass of herbivores across the reef zones was similarly analysed, with a $\log (x+1)$ transformation applied to the data to meet the ANOVA assumptions. Where differences in abundance or biomass between reef zones were found to be significant, Student-Newman-Keuls post hoc tests (SNK) were carried out to investigate those differences.

For each of the 3 dominant species of herbivore, differences in daily impact across the reef gradient (zones) were compared using a 1-way ANOVA (no significant effect of site on herbivore abundance had been detected). To make statistical impact comparisons, the compound variance associated with the impact value calculated as a product of means had to be deconstructed. The variance associated with bite size and number of bites per day was removed, since this was common across zones. Impact variables for each size class of each species were recalculated based on the mean bite size and mean number of bites per day, but multiplied by individual replicates of abundances obtained from the visual censuses. Data for each species were square-root or log-transformed as necessary to meet ANOVA assumptions of normality and homoscedasticity. Significant differences in the mean impact level between reef zones were investigated with post hoc tests (SNK).

Monthly (28 d) population impacts across the reef gradient for the 2 scarid species (Scarus rivulatus and Chlorurus microrhinos) were summed to give an impact estimate at the family level. The relationship between the impact of each group of grazers and the relative abundance of macroalgae across the reef gradient (excluding the reef slope) was then investigated using 2 bivariate correlations.

\section{RESULTS}

\section{Distribution of herbivore abundance and biomass}

A total of 27 species of roving herbivores were reported in the visual censuses. At the assemblage level there were no effects of site on either the total abundance (square-root transformed) (ANOVA, $F_{1,50}=$
1.617, $\mathrm{p}=0.209$ ) or the total biomass of herbivores ( $\log$ $[x+1]$ transformed) (ANOVA, $F_{1,50}=2.335, p=0.133$ ). There was also no significant interaction between the 2 factors of Site and Zone for either abundance (ANOVA, $F_{4,50}=0.621, \mathrm{p}=0.650$ ) or biomass (ANOVA, $\left.F_{4,50}=0.420, \mathrm{p}=0.794\right)$, suggesting that the site effect did not vary across the reef gradient. Data were therefore pooled across the 2 sites for presentation (Fig. 2).

Total herbivore abundance varied significantly across the reef zones (ANOVA, $F_{4,50}=14.813$, p < 0.05) (Fig. 2a). SNK tests revealed a significantly higher mean abundance of herbivores on the reef crest (0.18 ind $\left.\mathrm{m}^{-2} \pm 0.03 \mathrm{SE}\right)$ and outer flat $(0.15 \pm 0.03)$, than on the slope $(0.07 \pm 0.02)$, middle flat $(0.04 \pm 0.01)$ and inner flat $(0.02 \pm 0.01)$ (Fig. $2 \mathrm{a})$. From the reef crest to the inner reef flat there was an 8-fold decrease in the abundance of herbivores observed.

The distribution of herbivore biomass also showed significant variation across the reef gradient (ANOVA, $F_{4,50}=22.096, \mathrm{p}<0.05$ ) (Fig. 2b). This decrease was pronounced with an average 240 -fold difference in the biomass between the reef crest and the inner reef flat (Fig. 2b). Although the abundance of herbivores at the outer flat was similar in magnitude to that observed at the reef crest, the assemblage was composed predominately of juvenile scarids 5 to $10 \mathrm{~cm}$ in length. This group contributed little in terms of biomass and resulted in the outer flat displaying a total biomass level of only $9.5 \mathrm{~g} \mathrm{~m}^{-2}( \pm 2.8 \mathrm{SE})$, which was statistically similar to the level of biomass on the reef slope (Fig. 2b). The middle flat and inner flat formed a third statistically homogenous subset, displaying almost insignificant levels of herbivore biomass (Fig. 2b).

The biomass of the 27 species of roving herbivorous fishes observed in visual censuses was dominated by 3 species, Scarus rivulatus, Chlorurus microrhinos and Siganus doliatus (Fig. 2b). At the reef crest these 3 species made up an average of $89 \%$ of the total biomass of roving herbivores (vs. $80 \%$ on the reef slope and $64 \%$ on the outer reef flat). Territorial damselfish averaged $0.38( \pm 0.03 \mathrm{SE})$ ind. $\mathrm{m}^{-2}$ on the reef crest compared with $0.46( \pm 0.07)$ on the middle reef flat and 0.43 $( \pm 0.08)$ on the inner reef flat.

\section{Impact of an individual}

Feeding rates varied widely among species (Table 1). Scarus rivulatus individuals had consistently high bite rates irrespective of the size class (approximately 13000 to 15000 bites $\mathrm{d}^{-1}$ ). Juvenile Siganus doliatus took 14000 bites $\mathrm{d}^{-1}$, but this rate decreased markedly for adults (5800). The largest species, Chlorurus microrhinos, had the lowest reported rates (5000 bites $\mathrm{d}^{-1}$ ). 
Table 1. Scarus rivulatus, Chlorurus microrhinos and Siganus doliatus. Mean number of bites $( \pm \mathrm{SE})$ taken over the course of a day by individual size classes of $S$. rivulatus, $C$. microrhinos and $S$. doliatus. Total feeding rate for each day was calculated from integration of the equation fitted to the diurnal feeding pattern (from start of feeding to sunset). Mean values were calculated from the average of $4 \mathrm{~d}$ of observations ( $3 \mathrm{~d}$ in the case of C. microrhinos)

\begin{tabular}{|lcc|}
\hline Species & $\mathrm{n}$ & Bites d $^{-1}$ \\
\hline Scarus rivulatus & & \\
Small $(5-10 \mathrm{~cm})$ & 137 & $13699 \pm 1400$ \\
Medium $(11-25 \mathrm{~cm})$ & 174 & $15058 \pm 1316$ \\
Large $(>25 \mathrm{~cm})$ & 165 & $15585 \pm 856$ \\
Chlorurus microrhinos & 132 & $5188 \pm 266$ \\
Siganus doliatus & & \\
Small $(5-10 \mathrm{~cm})$ & 71 & $14320 \pm 913$ \\
Medium $(11-20 \mathrm{~cm})$ & 185 & $8943 \pm 1017$ \\
Large $(>20 \mathrm{~cm})$ & 233 & $5869 \pm 784$ \\
\hline
\end{tabular}

The impact of an individual bite of Scarus rivulatus in terms of area of reef grazed increased substantially with the length of the individual. A bite from a large (>25 cm TL) fish grazed, on average, a $69.5 \mathrm{~mm}^{2}$ $( \pm 4.2 \mathrm{SE})$ area of reef, which was more than double the average impact of a medium-sized (11-25 cm TL) fish of $27.8 \mathrm{~mm}^{2}( \pm 2.7)$. The mean area grazed by a small $(5-10 \mathrm{~cm} \mathrm{TL})$ individual was just $2.9 \mathrm{~mm}^{2}( \pm 0.5)$. Similarly, the volume of material removed from the reef in a single bite by Siganus doliatus increased substantially with fish size. A large individual (>20 cm TL) removed, on average, $7.4 \mathrm{~mm}^{3}( \pm 0.5 \mathrm{SE})$ of material per bite, more than 3 times the average volume of $2.1 \mathrm{~mm}^{3}$ $( \pm 0.2)$ removed by medium sized fishes. Again, the impact of small (5-10 cm TL) individuals was minimal, with a mean volume of just $0.12 \mathrm{~mm}^{3}( \pm 0.03)$ per bite.

\section{Overall system impact}

For each species the estimated grazing impact in a particular zone showed significant variation across the reef gradient (Fig. 3, Table 2). All 3 species were found to exert a significantly higher impact on the reef crest, although in the case of Scarus rivulatus the impact at the outer reef flat was not significantly different (Fig. 3a). For both Chlorurus microrhinos and Siganus doliatus the middle and inner reef flat formed a homogenous subset with significantly lower grazing impact than observed for the other reef zones (Fig. $3 \mathrm{~b}, \mathrm{c})$. For C. microrhinos the outer reef flat was also found to experience an almost insignificant impact in terms of grazing, meaning that only the reef slope and crest were found to be subject to a significant amount of grazing by this species (Fig. 3b).
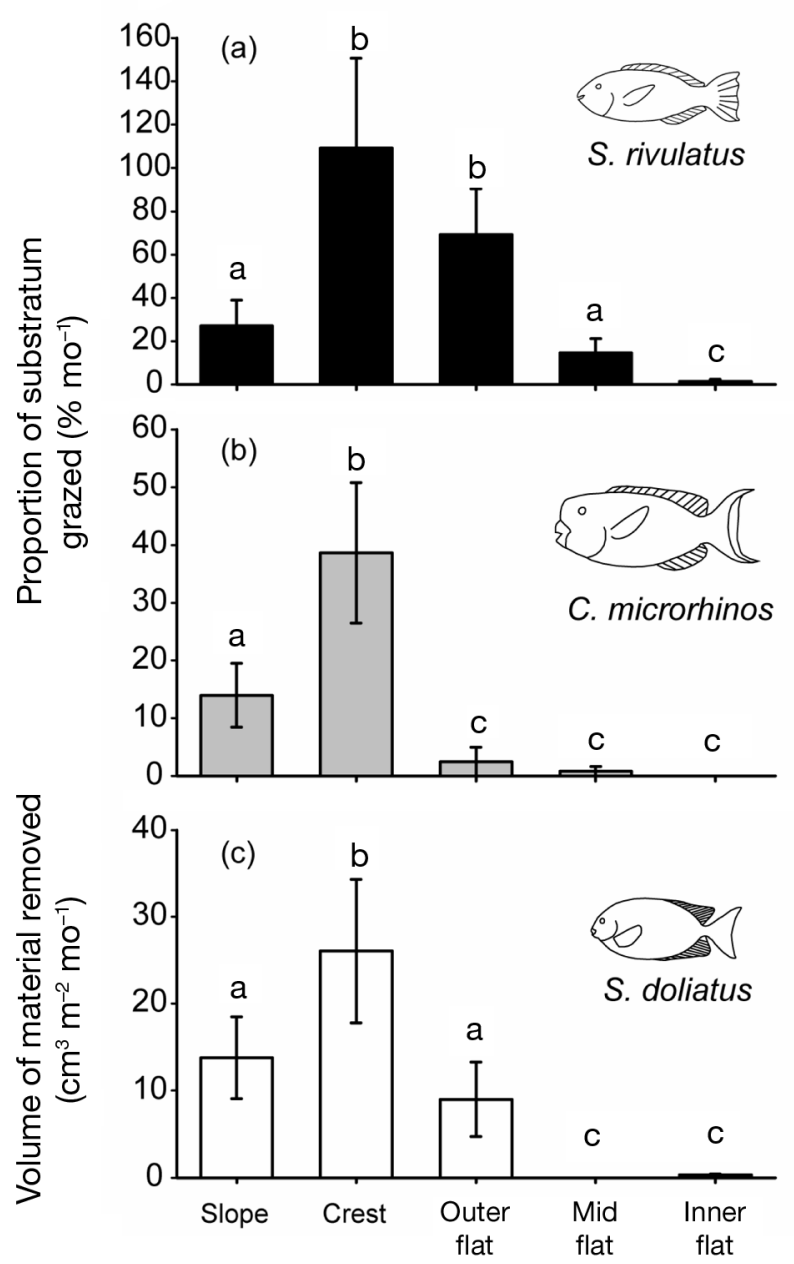

Fig. 3. Scarus rivulatus, Chlorurus microrhinos and Siganus doliatus. Impact of population of (a) $S$. rivulatus: percentage $( \pm \mathrm{SE})$ of each $\mathrm{m}^{2}$ area of reef grazed per month, (b) C. microrhinos: percentage $( \pm \mathrm{SE})$ of each $\mathrm{m}^{2}$ area of reef grazed per month; and (c) $S$. doliatus: volume $( \pm \mathrm{SE})$ of algal material removed from each $\mathrm{m}^{2}$ per month. Monthly impact values were estimated by multiplying daily rates by 28 . Overall SE values were calculated using the 3-term Goodman equation (details in 'Materials and methods'). Homogeneous subsets (based on SNK tests) are indicated with letters in common above the bars $(\mathrm{a}, \mathrm{b}, \mathrm{c})$

For the population of Scarus rivulatus, estimates of the monthly impact showed that each square metre of reef area on the crest would be grazed, on average, once during that period (Fig. 3a). In contrast, an average of just $27 \%( \pm 12 \% \mathrm{SE})$ of each square metre patch of reef on the slope and only $1.3 \%( \pm 1 \%)$ on the inner reef flat would be grazed (Fig. 3a). The impact of $S$. rivulatus at the reef crest was driven primarily by the grazing of large individuals despite their lower abundance compared with the other size classes (Fig. 4a). At the outer flat, medium sized individuals dominated both in terms of abundance and grazing impact, with the high abundance of small individuals making only a small contribution to grazing impact (Fig. 4a). 
Table 2. Scarus rivulatus, Chlorurus microrhinos and Siganus doliatus. Results of 1-way ANOVA comparing the inferred impact across the reef gradient (zones) for $S$. rivulatus (data square-root transformed), C. microrhinos (data square-root transformed) and $S$. doliatus (data $\log [x+1]$ transformed). ${ }^{*}$ Significance at the 0.05 level

\begin{tabular}{|lrccc|}
\hline Source of variation & df & MS & $F$ & $\mathrm{p}$ \\
\hline Scarus rivulatus & & & & \\
$\quad$ Zone & 4 & 0.0547 & 13.725 & $0.001^{*}$ \\
$\quad$ Error & 55 & 0.0039 & & \\
$\quad$ Total & 60 & & & \\
Chlorurus microrhinos & & & \\
$\quad$ Zone & 4 & 0.0215 & 13.157 & $0.001^{*}$ \\
Error & 55 & 0.0016 & & \\
$\quad$ Total & 60 & & & \\
Siganus doliatus & & & & \\
$\quad$ Zone & 4 & 0.1580 & 21.885 & $0.001^{*}$ \\
Error & 55 & 0.0072 & & \\
$\quad$ Total & 60 & & & \\
\hline
\end{tabular}

The areal impact of Chlorurus microrhinos at the crest inferred from presence meant that, on average, almost $40 \%( \pm 12 \% \mathrm{SE})$ of each square metre patch of reef would be subject to grazing over the month (Fig. 3b). The volume of algal material removed from the reef crest by the dominant cropper of algae within the system, Siganus doliatus, was calculated to be, on average, $26 \mathrm{~cm}^{3}( \pm 8.2)$ over the month compared with an average rate of removal of just $0.3 \mathrm{~cm}^{3}$ $( \pm 0.1)$ per month on the inner flat (Fig. 3c). The impact of $S$. doliatus at the slope, crest and outer reef flat was driven by the feeding of medium-sized individuals, while large individuals contributed a significant proportion of algal removal on the slope and reef crest (Fig. 4b).

\section{Relationship between herbivore impact and distribution of macroalgae}

Species of macroalgae observed on the inner and middle reef flat in Pioneer Bay included the phaeophytes, Sargassum and Padina, and the calcified chlorophyte, Halimeda opuntia. At the outer flat the rhodophyte, Galaxaura rugosa, was predominant. Overall, macroalgal cover was very high on the inner and middle reef flats, covering an average of $41 \%$ $( \pm 2.8 \% \mathrm{SE})$ and $38 \%( \pm 2.1 \%)$ of the substratum, respectively (Fig. 5, Table 3). At the reef crest, macroalgal cover dropped to just $1.5 \%( \pm 0.6 \%)$ (Fig. 5). This decrease in macroalgal cover across the reef gradient was negatively correlated with both the feeding impact of the 2 scarid species (Pearson's $r=-0.991, p<$ 0.05) and the impact of Siganus doliatus (Pearson's r =

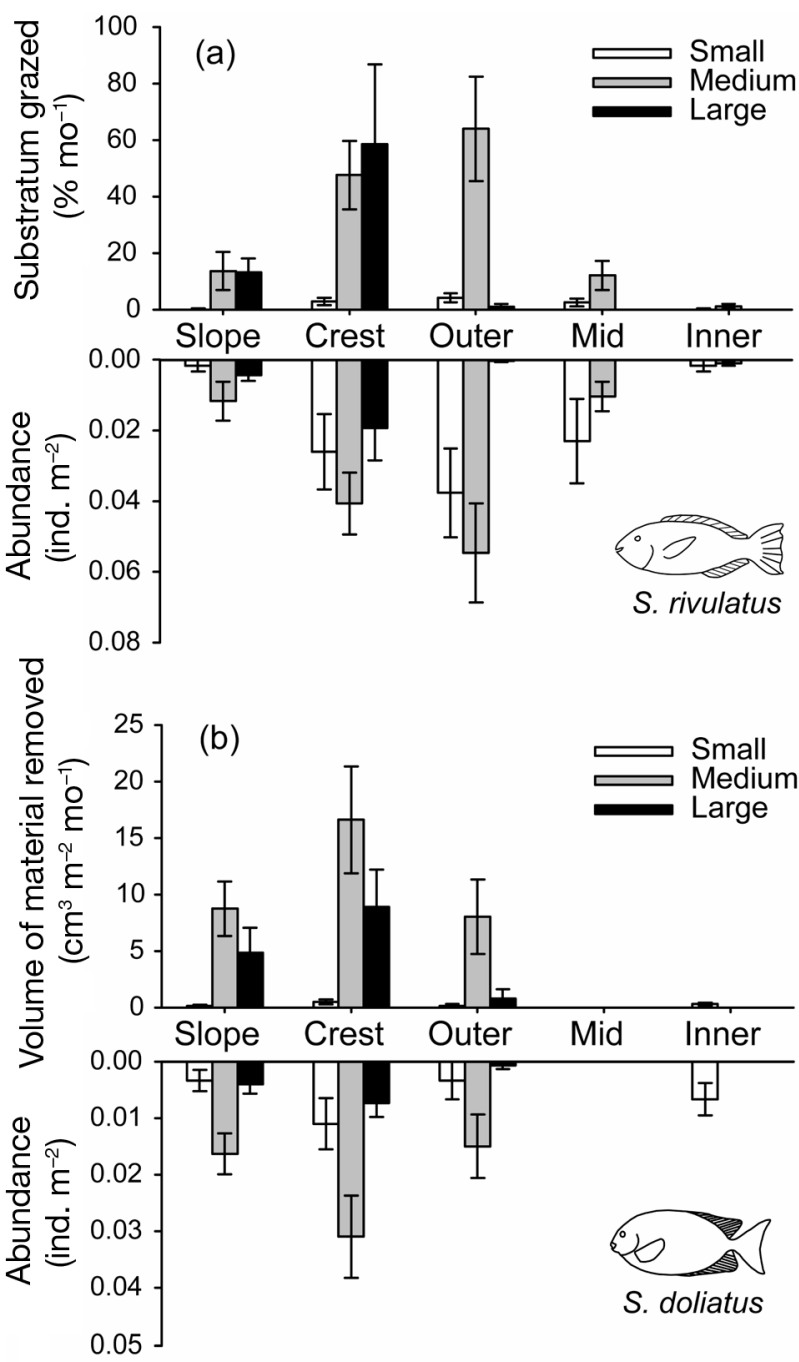

Fig. 4. Scarus rivulatus and Siganus doliatus. Disturbance impact of individual size classes of (a) S. rivulatus (estimated percentage of reef area grazed per month $\pm \mathrm{SE}$ ) and (b) $S$. doliatus (volume of algal material removed per month $\pm \mathrm{SE}$ ) in relation to abundance of individual size classes (ind. $\mathrm{m}^{-2} \pm \mathrm{SE}$ )

-0.965, p < 0.05) (Fig. 5). The variability in macroalgal abundance appeared to be dominated by the feeding impact of the 2 scarids (partial correlation, $r=-0.932$, $\mathrm{p}<0.05$ ) rather than the siganid (partial correlation, $\mathrm{r}=0.7064, \mathrm{p}=0.501$ ).

A significant negative correlation was observed between the estimated impact of the 2 scarid species, Scarus rivulatus and Chlorurus microrhinos, and the abundance of macroalgae across the reef flat and crest (Pearson's $r=-0.991, p<0.05$ ) (Fig. 5). A significant negative correlation was also observed between the impact of Siganus doliatus and abundance of macroalgae across the reef gradient (Pearson's $\mathrm{r}=-0.965, \mathrm{p}<$ 0.05) (Fig. 5). 

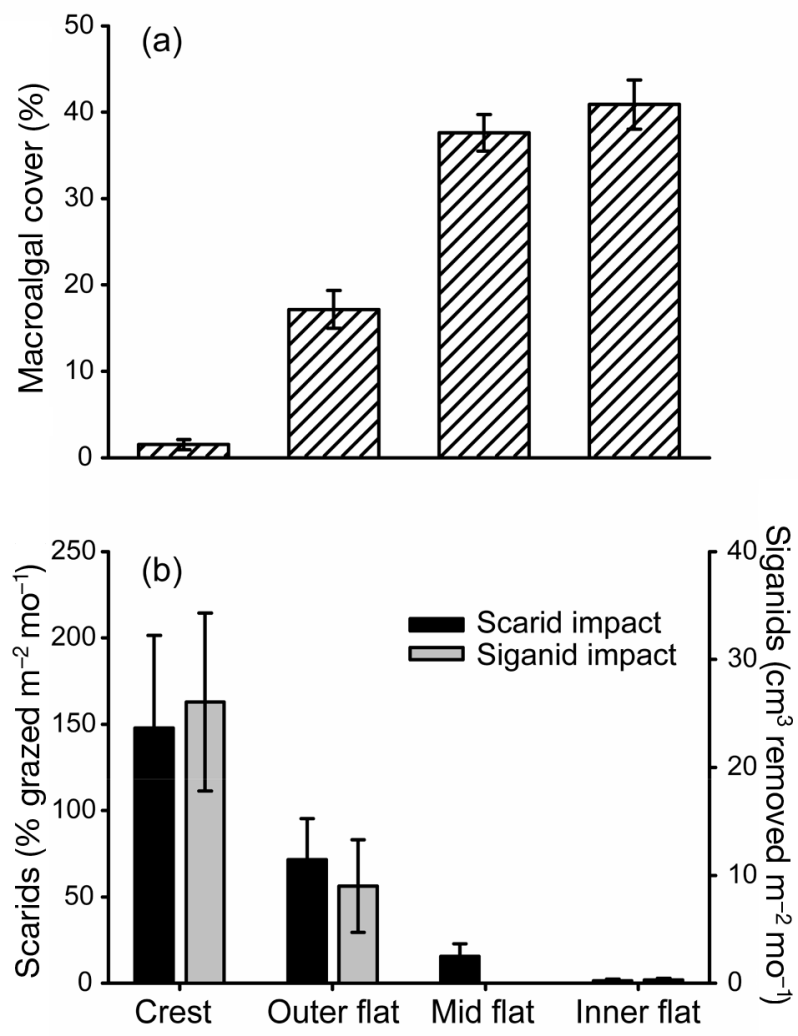

Fig. 5. Relationship between (a) the percentage $( \pm \mathrm{SE})$ macroalgal cover and (b) the measured monthly impact $( \pm \mathrm{SE})$ of the 3 dominant species of herbivorous fishes across the reef gradient at Pioneer Bay

\section{DISCUSSION}

The strong negative relationship between macroalgal abundance and herbivore impact recorded across the reef depth gradient in Pioneer Bay provides a clear quantification of potential herbivore-mediated disturbance. Although previous workers have recorded comparable patterns in the Caribbean (e.g. Hay et al. 1983, Lewis \& Wainwright 1985), the present study provides a detailed quantification of potential grazing intensity across an Indo-Pacific reef gradient. The decline in herbivore impact across the reef flat showed a strong concordant pattern in all 3 dominant fish species despite their different sizes, feeding modes and phylogenetic affinities. The impact of Scarus rivulatus increased 109-fold from the inner flat out to the reef crest, the impact of Siganus doliatus increased 83-fold and the impact of Chlorurus microrhinos was concentrated almost entirely at the crest with no impact on the inner flat.

Several hypotheses have been proposed to explain the observed differences in grazing impact across reef depth gradients, including several factors that could potentially limit grazer access to the reef flat and cre-
Table 3. Results of benthic cover surveys. Cover represents the mean percentage intercept from $12 \times 10 \mathrm{~m}$ transects $( \pm$ SE). EAM: epilithic algal matrix (turf)

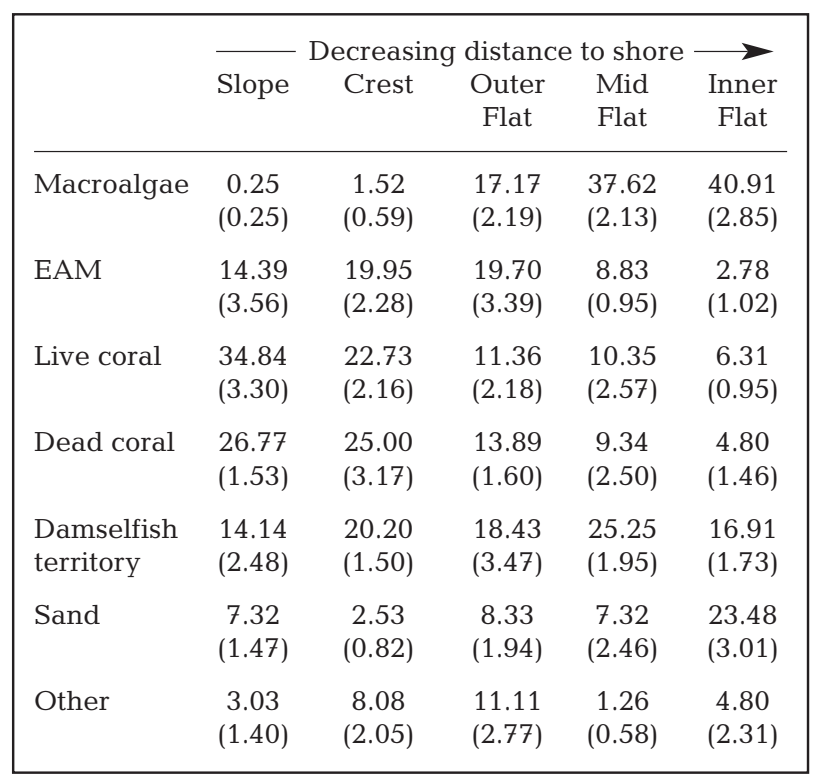

ate a 'spatial refuge' from herbivory (Hay 1981a). These factors include: the energetic costs of dealing with high wave energy (Hay 1981b); the physical constraints of the tidal regime providing sufficient access to the habitats (Burrows 1994); the effect of territorial fishes such as pomacentrids (Ceccarelli et al. 2005b); or the lack of availability of refuges from predation on the topographically simple reef flat (McCook 1997).

No experimental evidence has yet established the relative importance of these factors in driving the observed patterns. However, in the present study the relative impact of some of these factors can be evaluated. For example, Pioneer Bay, on the leeward side of an inshore reef, represents the lowest end of the wave energy spectrum (Bellwood \& Wainwright 2001) making it unlikely that energetic costs are a major factor in keeping herbivores from the nearshore region. Moreover, the reef crest and reef flat experience the highest levels of flow velocity (Fulton \& Bellwood 2005) and should have the lowest herbivore activity. Clearly, therefore, energetic constraints on herbivores from wave action are not a significant factor affecting herbivore impacts in Pioneer Bay.

Tidal emergence curves for Pioneer Bay suggest that, over the whole tidal cycle, the inner reef flat may be exposed for up to 30 to $40 \%$ of the day, compared with 20 to $25 \%$ for the outer reef flat and just $5 \%$ for the reef crest (cf. Kenny 1979). Hence, it is likely that lack of access to the reef habitats in question may limit the extent to which grazing can take place. However, the quantification of herbivore impacts in this study 
was based on fish abundance conducted at high tide, in order to eliminate such effects. Even at high tide, therefore, potential herbivore impact based on biomass showed a 240 -fold decrease across the reef flat (versus a 2-fold decrease in availability). This difference suggests that whilst physical constraints related to water level may contribute to relative levels of herbivory, they are unlikely to be driving the inferred patterns of herbivory across the reef.

Territorial damselfish have been reported to reduce rates of feeding by herbivores by attacking individuals and prematurely terminating feeding forays (Robertson et al. 1976). However, abundances of species of pomacentrids known to display territorial behaviour recorded during this study did not show a dramatic increase on the nearshore reef zones that could account for the observed differences in herbivore impact (crest $0.38 \mathrm{~m}^{-2}$, middle flat $0.46 \mathrm{~m}^{-2}$, inner flat $0.43 \mathrm{~m}^{-2}$ ). Thus, although pomacentrids may reduce levels of herbivory, their impact is probably relatively even across the reef gradient and is unlikely to be driving the observed differences in herbivory (cf. Ceccarelli et al. 2005a).

The idea that the reef flat, because of its limited topographic complexity, represents an uninviting habitat in terms of predator avoidance may explain the lower biomass of herbivores in the nearshore zones. Although no instances of predation were witnessed, the presence of large piscivores such as Caranx ignoblis, Carcharinus melanopterus and Triaenodon obesus on the reef flat was noted, along with aerial avian predators including Pandion haliaetus, Haliastur indus and Haliaeetus leucogaster. The suggestion that there may be a causative relationship between the lack of predator refuges and the low levels of herbivore impact, although not observed, could be valid.

An alternative to these hypotheses relates to algal quality across the gradient. Several studies have found decreasing productivity of algae with distance from the reef crest (e.g. Klumpp \& McKinnon 1992, Russ 2003). Russ (2003) also demonstrated a correlation between algal productivity and herbivore biomass across a reef gradient. Levels of herbivore impact could, however, be either cause or consequence of the patterns of algal productivity over the reef (Russ 2003). The higher levels of algal productivity observed in areas closer to the reef crest may be a result of the fishes congregating in those zones (for reasons including those outlined above) and subjecting the reef to higher levels of grazing intensity. Increased intensity of grazing increases the productivity of vegetation in freshwater systems (Porter 1976). However, as Russ (2003) pointed out, the almost 3-fold differential in algal productivity measured across a reef on the Great Barrier Reef was much greater than any productivity increase previously recorded from experimental manipulations of herbivore grazing, suggesting that grazing intensity alone could not be driving the observed patterns of productivity.

The higher levels of herbivore biomass observed at the reef crest may, therefore, represent a consequence of differences in algal productivity rather than a cause. Fishes may be responding to higher food quality in this zone. This may also apply to those 'herbivorous' species that use detrital resources, which also concentrate in the crest region (Purcell \& Bellwood 2001, Wilson et al. 2003). Rather than the influence of tidal regime or relative habitat safety, the pattern of herbivore grazing across the reef gradient may be attributable to the fact that the reef crest has more to offer the discerning forager in terms of nutritional quality. At present, the relative importance of these alternative factors, predation rate versus food quality, remains to be determined.

Regardless of the factors shaping herbivory, the level of disturbance received by an area in terms of herbivore grazing activity can influence the path of algal succession (Steneck 1988). Within coral reef systems, the removal of herbivores, either via artificial caging experiments or through impacts of overfishing and disease, has been associated with the development of benthic communities dominated by late successional stage species of macroalgae (Hughes 1994, Smith et al. 2001). The impact of herbivores on algal communities can, therefore, be recast as a disturbance force (Steneck 1988). Certain levels of disturbance (measured in terms of intensity and frequency) generate predictable algal community assemblages (Steneck et al. 1991, Steneck \& Dethier 1994). The intensity with which a particular area of reef is grazed is a function of the feeding rate of each species, the bite size (size of mouthparts), nature and quantity of material removed and the foraging behaviour or relative mobility of the herbivore (Carpenter 1986, Steneck 1988). This model necessarily represents a simplification of the complex interaction between specific herbivores and the algal community (Carpenter 1986); however, it remains a useful framework for considering the effect of changing levels of herbivory on algal community succession.

Models of algal community succession predict that low grazing intensity will lead to the development of climax communities characterized by slow growing taxa such as Sargassum spp. and Padina spp. (Steneck \& Dethier 1994, McClanahan 1997). The gradient in grazing intensity across the reef measured in this study is certainly marked. At the daily bite rates recorded, each square metre patch of reef would be grazed by scarids once every $19 \mathrm{~d}$ on the crest, but only once every $5.5 \mathrm{yr}$ on the inner flat. Seen in these terms, the correlation between low herbivore disturbance levels on the inner and middle reef flats and high levels of 
macroalgae in these areas appears to support the herbivore-induced disturbance model of algal community composition proposed by Steneck \& Dethier (1994). However, it is stressed that causality has not been demonstrated and other factors such as nutrient concentration may also play a role in shaping the distribution of macroalgae (Schaffelke 1999; see also Bellwood et al. 2006).

The size of the gradient in herbivore impact quantified for Pioneer Bay is interesting as it may provide an example of an extreme end of the spectrum in herbivore impact differentials in the context of reefs on the Great Barrier Reef. The herbivore biomass contributing to the differences in disturbance impact on the reef crest in Pioneer Bay was more than 2.5 times that observed on the reef slope, almost 40 times that observed on the middle flat and more than 240 times greater than that observed on the inner reef flat. These differences across the reef gradient are more extreme than those reported by Russ (2003) for an outer shelf reef on the Great Barrier Reef where the biomass of herbivores on the reef crest was 7 times greater than that on the reef slope and 2.3 times greater than on the reef flat. The greater extremes measured for an inner shelf in Pioneer Bay may, in part, provide an indication of why these reefs display greater macroalgal development than outer shelf reefs on the Great Barrier Reef.

Finally, in relation to the particular location studied, the results highlight the fact that the biomass of herbivores within Pioneer Bay is dominated by 3 species: Scarus rivulatus, Chlorurus microrhinos and Siganus doliatus. These 3 species represent 3 distinct functional groups in terms of their feeding behaviour. S. rivulatus is classified as a scraper of the reef substratum (Bellwood \& Choat 1990), C. microrhinos as a bioeroder of reef substrata (Bellwood \& Choat 1990) and S. doliatus a cropper of turf algae (Russ 1984). These 3 functional groups have been identified by Bellwood et al. (2004) as playing critical roles in the ability of reefs to deal with large scale disturbance events such as bleaching, disease and cyclones.

The abundances of these 3 species in comparison with that of their functional equivalents suggests that the system in Pioneer Bay relies heavily on just one species within each functional group. Based on the low abundances of functional equivalents such as Scarus schlegeli (a scraper), Chlorurus sordidus (a bioeroder) and Siganus puellus (a cropper) observed within Pioneer Bay during this study, it could be argued that the system currently displays limited functional redundancy. Maintenance of the benthic community composition appears to be heavily reliant on these 3 species. It is usually assumed that reefs of the Great Barrier Reef, by virtue of their species richness, display considerable functional redundancy (McManus \& Polsenberg
2004). However, the species breakdown of biomass recorded in Pioneer Bay revealed that even diverse systems, such as this one, may rely heavily on a small number of species to perform specific functions. If this is the case, then for certain reefs, identification of management protection priorities down to the species level may be vital (cf. Bellwood et al. 2003, 2006).

Variation among reef herbivores has been known for many years (e.g. Hatcher 1981, Lewis 1985, Carpenter 1986, Choat 1991). Only now has the critical importance of such variation come to the fore with the global threats to coral reefs, the prevalence of coral-algal phase shifts, and the need to understand the basis of reef resilience In this context, understanding the absolute quantitative nature of interactions at the species level is critical. This includes an appreciation of the effect on the system of individual components of the guild in terms of feeding rates, foraging behaviour, bite size and feeding selectivity. Only then can managers start to understand how spatial variation in herbivore distribution might be driving variation in algal community composition and, ultimately, reef resilience.

Acknowledgements. We thank the staff of Orpheus Island Research Station for provision of facilities; C. Mantyka, T. Sunderland, C. Ryen, C. Fulton, A. Gonzalez-Cabello and A. Hoey for field assistance; S. Connolly, C. Fulton, A. Hoey and G. Russ for helpful discussions and 4 anonymous reviewers for constructive comments. This work was supported by the Great Barrier Reef Marine Park Authority and the Australian Research Council (D.R.B.).

\section{LITERATURE CITED}

Bellwood DR (1995) Direct estimate of bioerosion by two parrotfish species, Chlorurus gibbus and $C$. sordidus, on the Great Barrier Reef, Australia. Mar Biol 121:419-429

Bellwood DR, Choat JH (1990) A functional analysis of grazing in parrotfishes (family Scaridae): the ecological implications. Environ Biol Fishes 28:189-214

Bellwood DR, Wainwright PC (2001) Locomotion in labrid fishes: implications for habitat use and cross-shelf biogeography on the Great Barrier Reef. Coral Reefs 20:139-150

Bellwood DR, Hoey AS, Choat JH (2003) Limited functional redundancy in high diversity systems: resilience and ecosystem function on coral reefs. Ecol Lett 6:281-285

Bellwood DR, Hughes TP, Folke C, Nystrom M (2004) Confronting the coral reef crisis. Nature 429:827-833

Bellwood DR, Hughes TP, Hoey AS (2006) Sleeping functional group drives coral reef recovery. Curr Biol 16:2434-2439

Bruggemann JH, van Oppen MJH, Breeman AM (1994) Foraging by the stoplight parrotfish Sparisoma viride. I. Food selection in different, socially determined habitats. Mar Ecol Prog Ser 106:41-55

Bruggemann, JH, van Kessel AM, van Rooij JM, Breeman AM (1996) Bioerosion and sediment ingestion by the Caribbean parrotfish Scarus vetula and Sparisoma viride: implications of fish size, feeding mode and habitat use. Mar Ecol Prog Ser 134:59-71

Burrows MT (1994) An optimal foraging and migration model 
for juvenile plaice. Evol Ecol 8:125-149

Carpenter RC (1986) Partitioning herbivory and its effects on coral reef algal communities. Ecol Monogr 56:345-364

Ceccarelli DM, Jones GP, McCook LJ (2005a) Effects of territorial damselfish on an algal-dominated coastal coral reef. Coral Reefs 24:606-620

Ceccarelli DM, Jones GP, McCook LJ (2005b) Foragers versus farmers: contrasting effects of two behavioural groups of herbivores on coral reefs. Oecologia 145:445-453

Choat JH (1991) The biology of herbivorous fishes on coral reefs. In: Sale PF (ed) The ecology of fishes on coral reefs. Academic Press, San Diego, CA, p 120-155

Choat JH, Clements KD, Robbins WD (2002) The trophic status of herbivorous fishes on coral reefs 1: dietary analyses. Mar Biol 140:613-623

Fulton CJ, Bellwood DR (2005) Wave-induced water motion and the functional implications for coral reef fish assemblages. Limnol Oceanogr 50:255-264

Hatcher BG (1981) The interaction between grazing organisms and the epilithic algal community of a coral reef. Proc 4th Int Coral Reef Symp 2:515-524

Hatcher BG (1983) Grazing in coral reef ecosystems. In: Barnes DJ (ed) Perspectives on coral reefs. Brian Clouston, Canberra, p 164-179

Hay ME (1981a) Herbivory, algal distribution and the maintenance of between habitat diversity on a tropical fringing reef. Am Nat 118:520-540

Hay ME (1981b) Spatial patterns of grazing intensity on a Caribbean barrier reef herbivory and algal distribution. Aquat Bot 11:97-110

Hay ME, Colburn T, Downing D (1983) Spatial and temporal patterns in herbivory on a Caribbean fringing reef: the effects on plant distribution. Oecologia 58:299-308

Hixon MA, Brostoff WN (1996) Succession and herbivory: effects of differential fish grazing on Hawaiian coral-reef algae. Ecol Monogr 66:67-90

Hughes TP (1994) Catastrophes, phase shifts, and large-scale degradation of a Caribbean coral reef. Science 265: $1547-1551$

Hughes TP, Bellwood DR, Folke C, Steneck RS, Wilson J (2005) New paradigms for supporting the resilience of marine ecosystems. Trends Ecol Evol 20:380-386

Kenny R (1979) Predicted, actual and effective tidal emersion at Townsville. Proc R Soc Queensl 90:113-116.

Klumpp DW, Polunin NVC (1989) Partitioning among grazers of food resources within damselfish territories on a coral reef. J Exp Mar Biol Ecol 125:145-169

Klumpp DW, McKinnon AD (1992) Community structure, biomass and productivity of epilithic algal communities on the Great Barrier Reef: dynamics at different spatial scales. Mar Ecol Prog Ser 86:77-89

Klumpp DW, McKinnon AD, Daniel P (1987) Damselfish territories: zones of high productivity on coral reefs. Mar Ecol Prog Ser 40:41-51

Kulbicki M, Guillemot N, Amand M (2005) A general approach to length-weight relationships for New Caledonian lagoon fishes. Cybium 29:235-252

Lewis SM (1985) Herbivory on coral reefs: algal susceptibility to herbivorous fishes. Oecologia 65:370-375

Lewis SM, Wainwright PC (1985) Herbivore abundance and grazing intensity on a Caribbean coral reef. J Exp Mar Biol

Editorial responsibility: Charles Birkeland (Contributing Editor), Honolulu, Hawaii, USA
Ecol 87:215-228

McClanahan TR (1997) Primary succession of coral-reef algae: differing patterns on fished versus unfished reefs. J Exp Mar Biol Ecol 218:77-102

McClanahan TR, Sala E, Stickels PA, Cokos BA, Baker AC, Starger CJ, Jones SH (2003) Interaction between nutrients and herbivory in controlling algal communities and coral condition on Glover's Reef, Belize. Mar Ecol Prog Ser 261: $135-147$

McCook LJ (1997) Effects of herbivory on zonation of Sargassum spp. within fringing reefs of the central Great Barrier Reef. Mar Biol 129:713-722

McManus JW, Polsenberg JF (2004) Coral-algal phase shifts on coral reefs: ecological and environmental aspects. Prog Oceanogr 60:263-279

Mumby PJ, Dahlgren CP, Harborne AR, Kappel CV and 10 others (2006) Fishing, trophic cascades and the process of grazing on coral reefs. Science 311:98-101

Nystrom M, Folke C, Moberg F (2000) Coral reef disturbance and resilience in a human-dominated environment. Trends Ecol Evol 15:413-417

Polunin NVC, Klumpp DW (1992) Algal food supply and grazer demand in a very productive coral-reef zone. J Exp Mar Biol Ecol 164:1-15

Polunin NVC, Harmelin-Vivien M, Galzin R (1995) Contrasts in algal food processing among five herbivorous coral reef fishes. J Fish Biol 47:455-465

Porter KG (1976) Enhancement of algal growth and productivity by grazing zooplankton. Science 192:1332-1334

Purcell SW, Bellwood DR (2001) Spatial patterns of epilithic algal and detrital resources on a windward coral reef. Coral Reefs 20:117-125

Robertson DR, Sweatman HPA, Fletcher EA, Cleland MG (1976) Schooling as a mechanism for circumventing the territoriality of competitors. Ecology 57:1208-1220

Russ GR (1984) Distribution and abundance of herbivorous grazing fishes in the central Great Barrier Reef. I. Levels of variability across the entire continental shelf. Mar Ecol Prog Ser 20:23-34

Russ GR (2003) Grazer biomass correlates more strongly with production than with biomass of algal turfs on a coral reef. Coral Reefs 22:63-67

Schaffelke B (1999) Short term nutrient pulses as tools to assess responses of coral reef macroalgae to enhanced nutrient availability. Mar Ecol Prog Ser 182:305-310

Smith JE, Smith CM, Hunter CL (2001) An experimental analysis of the effects of herbivory and nutrient enrichment on benthic community dynamics on a Hawaiian reef. Coral Reefs 19:332-342

Steneck RS (1988) Herbivory on coral reefs: a synthesis. Proc 6th Int Coral Reef Symp 1:37-49

Steneck RS, Dethier MN (1994) A functional group approach to the structure of algal-dominated communities. Oikos 69:476-498

Steneck RS, Hacker SD, Dethier MN (1991) Mechanism determining competitive dominance between crustose coralline algae: a herbivore-mediated reversal. Ecology 72:938-950

Wilson SK, Bellwood DR, Choat JH, Furnas MJ (2003) Detritus in the epilithic algal matrix and its use by coral reef fishes. Oceanogr Mar Biol Annu Rev 41:279-309

Submitted: July 15, 2006; Accepted: November 28, 2006

Proofs received from author(s): May 24, 2007 